\title{
Capitulación de la investigación científica contemporánea. Una revisión histórico-crítica
}

\author{
Capitulation of the contemporary scientific investigation. \\ A historical-critical revision
}

Jorge Gasca Salas*

Resumen: Este artículo de revisión crítica indaga sobre las condiciones epistemológicas que dan lugar a un paradigma histórico vigente como el que T.S. Kuhn denominó "ciencia normal", su predominio, sus tendencias empleadas de facto y la capitulación de las ciencias en general, las ciencias sociales en particular y buena parte de las investigaciones marxistas, desde hace décadas, sucumbiendo bajo una supuesta "pluralidad" ideológica "posmodernista", en aras de la llamada "teoría de la complejidad", el "pensamiento complejo" y la correspondiente "ciencia de la complejidad", pero profundamente positivista y antidialéctica.

Palabras clave: Investigación científica; dialéctica; positivismo; ciencia normal; "pensamiento complejo"; capitulación

\begin{abstract}
This article of critical revision investigates on the epistemological conditions that give place to a historical in force paradigm like that T.S. Kuhn named "normal science", his predominance, his trends used in fact and the capitulation of the sciences in general, the social sciences especially and a part of the marxist investigations, for decades, succumbing under a supposed ideological "plurality" "posmodernist", in the interests of the so called "complexity theory", the "complex thinking" and corresponding "science of the complexity", but deeply antidialectical and positivist.
\end{abstract}

Key words: Scientific investigation; dialectic; positivism; normal science; complex thinking; capitulation

Recibido: 3 agosto 2018 Aceptado: 23 noviembre 2018

\footnotetext{
* México / Autor / Doctor en filosofía por la UNAM / Profesor-Investigador del INSTITUTO POLITÉCNICO NACIONAL (IPN), Sección de Estudios de Posgrado e Investigación, Escuela Superior de Ingeniería y Arquitectura, Unidad Zacatenco. Derivaciones del Proyecto de Investigación «Tendencias de la refuncionalización y la 'gentrificación' en centros históricos de ciudades latinoamericanas» (SIP 2018 1978) desarrollado en el IPN / (jogasca@ipn.mx).
} 
La renuncia de los filósofos y de los políticos a la razón en virtud de su capitulación ante la realidad encubre, de todos modos, una forma mucho más grave de regresión y culmina inevitablemente en una confusión de la verdad filosófica...

Max Horkheimer: Crítica de la razón instrumental

\section{Introducción}

La turbulencia de nuestro tiempo es la manifestación de un reacomodo sistémico, un proceso en el que se transita de un mundo dual capitalismo-socialismo a otro dominado, casi por completo, por un proyecto de economía neoliberal caracterizado históricamente por el fracaso de proyectos de modernidad (capitalismo y socialismo real) que ha alcanzado el status de "crisis del orden civilizatorio", en el que se ha puesto en cuestión el mundo de la vida en su conjunto y ha acontecido, desde casi un cuarto de siglo (1989), la confirmación del desencanto de la modernidad como proyecto histórico de orden epocal. De ello dan cuenta por lo menos cuatro fenómenos básicos que trastocan todos los ámbitos de la vida incluyendo el académico: el neoliberalismo, la globalización, la llamada "posmodernidad", y el polisémico "desarrollo sostenible o sustentable".

Estos fenómenos histórico-ideológicos y culturales se mimetizan en el campo científico bajo figuras asociadas a ellos de manera determinante. El neoliberalismo aparece disfrazado de "pluralismo", "competencia". "libre participación", inclusión de "múltiples saberes" y una supuesta "neutralidad ideológica" ("objetividad científica"). La globalización cuya expresión es el tecnologismo científico, se encuentra permeado por la teoría de sistemas aplicada a amplios campos de la ciencia bajo la figura de la "teoría de la complejidad" y se manifiesta gracias a la circulación mundial del conocimiento a manera de una "estandarización del conocimiento". La "posmodernidad" aparece como traída al escenario mundial por la crisis del capitalismo desarrollista y la crisis del socialismo real bajo la figura de la incredulidad teóricopolítica. El "desarrollo sostenible", evidencia de manera palmaria del ecocidio mundial como resultado inocultable de la explotación irracional capitalista de la riqueza natural como mero "recurso".

No resulta tan evidente el ocultamiento causal cuando se vive una etapa de transición, como la que vivimos y atravesamos, caracterizada por la incertidumbre histórica, la despersonalización tecnológica, la incredulidad ideológica, la devastación de la naturaleza, la incertidumbre y el desasosiego, precisamente cuando hacen presa de la comprensión del porvenir desde la dimensión de la cuaterna antes citada.

En este nuevo orden mundial se emplaza, ineludible e indudablemente, también la necesidad de un reacomodo del saber científico y sus implicaciones metodológicas, mimetizadas bajo la figura de crisis de "paradigmas epistemológicos" en espera de ser teorizados, valorados, afirmados o negados, tras el redimensionamiento de sus alcances y limitaciones filosófico-científicas.

\section{Implicaciones ideológicas e histórico-políticas del progreso científico}

En los últimos dos siglos (XIX y XX) se ha concentrado el mayor cúmulo del progreso civilizatorio como una "prodigiosa abreviatura entera de la humanidad" 1 , han acontecido sucesos que dignifican el llamado "espíritu humano": en el siglo XIX, la electrificación de las ciudades; el desarrollo de las artes y de la filosofía; la teoría de la unificación de la electricidad y el magnetismo, de Maxwell; la teoría de la evolución, de Darwin; la invención del acero; el ferrocarril; las luchas de liberación de los pueblos latinoamericanos; la integración de los estados-nación; etcétera. En el siglo XX, se ha dado lugar a la edificación de las grandes metrópolis, que sin duda representan un potencial indiscutible del hecho de vivir en colectividad; la teoría de la relatividad de Einstein; la teoría de los "hoyos negros"; los viajes espaciales; el uso del

${ }^{1}$ Walter Benjamín, Tesis sobre la bistoria y otros escritos, México, Contrahistorias, 2005, p.30. 
viento y el sol para la generación de energías alternativas; etcétera. Sin embargo, y muy a nuestro pesar, en estos dos siglos se han manifestado actos humanos altamente deleznables que también han expresado la capacidad destructiva de los seres humanos como, en el siglo XIX, el llamado "siglo de las luces", el ímpetu colonialista (la guerra por el espacio que se ha registrado desde la "noche de los tiempos" en las luchas a muerte entre los "neandertales" contra el "homo sapiens") estadounidense contra México y América Latina en su conjunto, por sólo citar a una potencia imperialista; y las masacres del imperio de Napoleón III contra los obreros de la Comuna de París en la primavera de 1871. En el siglo XX “el siglo de las tinieblas"2 deja tras de sí una "pedagogía del terror": nazismo; apartheid; guerras coloniales; guerra fría; bomba atómica; etcétera; muy bien simbolizada por dos figuras ampliamente deleznables: el Gulag y Auschwits, los dos iconos que representan la tiranía que la humanidad ha sido capaz de conocer hacia ambos lados de los sistema ideológicos (izquierda y derecha).

Resulta de suma pertinencia y prioridad preguntar: ¿tiene esto algún nexo esencial con las consideraciones epistemológicas y los nuevos paradigmas de la investigación científica actual, la de los comienzos del siglo XXI?

En nuestra opinión sí: en el sentido teórico de la ciencia (y fundamentalmente de la filosofía) es el conocimiento del mundo ${ }^{3}$ y de todo lo que en él acontece; su sentido práctico es la transformación humana del mundo. ¿Pero cuál es el sentido y dirección de ese conocimiento y esa transformación? En ello radica la relación fin-medio, reuniéndose las causalidades, esencialidades y complejidades del uso humano de la ciencia. Se trata, de las implicaciones existentes en la relación ciencia y sociedad, que son revisadas en este trabajo y las cuales pretendemos que con estas líneas queden planteadas en su esencia.

A la relación ciencia-sociedad fueron dedicadas en el siglo XX obras-clave escritas por pensadores tales como Martin Heidegger (véase especialmente "La época de la imagen del mundo" y "La pregunta por la técnica"), Thomas Kuhn (Las estructuras de las revoluciones cientificas), Karl Popper (La sociedad abierta y sus enemigos), Max Horkheimer (Crítica de la razón instrumental) y, formando mancuerna Max HorkheimerTheodor Adorno (Dialéctica de la ilustración). Estas últimas constituyen dos obras controversiales del siglo XX. De las discusiones epistemológicas destacadas, es célebre también la polémica desatada en Alemania de los años 60's entre Popper y Adorno (a la que se sumaron Albert y Habermas), mejor recordada como "La disputa del positivismo en la sociología alemana". En estos autores y sus respectivas obras queda registro de lo dicho hasta aquí. ${ }^{4}$ Respecto a estos estudios haremos algunas consideraciones que consideramos necesario destacar.

\section{Los criterios de la periodización histórica de la investigación científica}

Resulta interesante e imprescindible reflexionar sobre aquellos criterios que han constituido los fundamentos para construir periodizaciones vinculadas con el progreso científico. Gaston Bachelard, por citar sólo a uno de los teóricos-pivote del pensamiento francés que permiten comprender el desarrollo de la ciencia, divide el pensamiento científico en tres períodos:

El primer período, que representa el estado precientífico, comprendería a la vez la antigüedad clásica y los tiempos de renacimiento y de nuevos esfuerzos, con los siglos XVI, XVII y aun el XVIII.

\footnotetext{
2 Bolívar Echeverría, "Introducción: Benjamín, la condición judía y la política", en Tesis sobre la historia y otros fragmentos, México, Contrahistorias, 2005, p.10.

3 Denominamos "mundo" a la "realidad" en su conjunto: el cosmos; la vida planetaria de la Tierra (naturaleza biológica), el único planeta que hasta hoy sabemos que la contiene; las sociedades humanas (el Hombre); los fenómenos de la mente humana y los productos del pensamiento; a lo cual, en suma le llamamos "Universo" o simplemente "Naturaleza".

${ }^{4}$ No olvidamos las obras-clave que se han escrito en el seno del marxismo, tales como Marxismo y filosofia (Karl Korsch), Historia y conciencia de clase (Georg Lukács), "Tesis sobre la historia” (Walter Benjamin), El Hombre unidimensional (Hebert Marcuse) y Ciencia y técnica como "ideología" (Jürgen Habermas), entre otras.
} 
El segundo período, que representa el estado cientifico, en preparación a fines del siglo XVIII, se extendería hasta todo el siglo XIX y comienzos del XX.

En tercer lugar, fijaríamos exactamente la era del nuevo espiritu cientifico en 1905, en el momento en el que la Relatividad einsteniena deforma conceptos primordiales que se creían fijados para siempre. A partir de esta fecha, la razón multiplica sus objeciones, disocia y reconfigura las nociones fundamentales y ensaya las abstracciones más audaces. ${ }^{5}$

Los criterios y fundamentos de tal referenciación histórico-epistemológica son la "razón" y su capacidad de abstracción puestas de manifiesto en una de las ciencias que ya en la Crítica de la razón pura, escrita por Kant en el último cuarto del siglo XVIII (1787) en la que se coloca a las matemáticas y a la física como ciencias ejemplares de un tipo de ciencia y de época nuevas. ${ }^{6}$ Es para nosotros evidente que tal elección radica en el prurito de "neutralidad" que las envuelve aun cuando ambas tienen como telón de fondo su desprendimiento de lo que se denominó "filosofía natural". Desde luego, sabemos también que los denominados aquí "criterios de periodización" son siempre subjetivos y depende de quién los elige, pero constituyen un indicio para la comprensión de la relación problemática ciencia-sociedad. Sin embargo, no es casual que, en la gran mayoría de los pensadores, a excepción de Heidegger, coinciden en considerar a la razón como punto de partida.

Para Horkheimer y Adorno7 (1998) la "razón", o bien, la "racionalidad" es una pretensión según la cual la sociedad en su conjunto representada por el más avanzado intento de la "ilustración francesa" se sobrepuso a la dominación que en los siglos anteriores a la lucha contra el "mito" propias del oscurantismo impuesto por las culturas ancestrales provenientes de la antigüedad (nomos) dominó el conjunto del "mundo de la vida" surcando todos los órdenes del pensamiento y de la vida en sociedad (demos) y política hasta la sobreposición de la "razón" en la constitución de la vida republicana sellada políticamente por la revolución francesa, con la cual se da paso al progreso civilizatorio con el que se inicia la integración de los poderosos estados nacionales europeos, aspecto que no hace sino confirmar lo que parece estar en el consenso del conjunto de pensadores europeos prefigurando un primer período del progreso científico y cultural que parte de criterios más bien ideológico políticos, los cuales son la manifestación de la "racionalidad científico-política" sobre la cual se levanta la civilización occidental en su conjunto iniciada por el mundo griego clásico cuya cúspide la configura el pensamiento de Platón y Aristóteles (siglo IV a.n.e.).

Una segunda etapa queda perfilada a partir del pensamiento cartesiano quien marcó la separación evidente entre el sujeto y el objeto, el hombre de la naturaleza. "Cogito ergo sum" ("pienso, luego existo"), es el referente que marca la separación clara entre el ser y el pensar hasta el momento en que la ilustración hace su entrada en la historia humana durante el siglo XVIII, cuyo icono histórico es "1789".

Con la Revolución Francesa se inicia la tercera etapa, coetánea con el desarrollo del capitalismo de la Revolución Industrial, del cual dan cuenta ya los pensadores clásicos Adam Smith, David Ricardo, K. Marx y Max Weber (desde luego, el gran teórico del racionalismo económico). Todos ellos desde referentes ideológicos distintos.

En Hegel y en Max Weber es perceptible la idea de que el stau quo, el capitalismo (llamado así en 1902 por Werner Sombart, Der moderne Kapitalismus) ${ }^{8}$ la razón alcanza su cúspide en el Estado, como "acción inteligente universal" y en el sistema económico "racional". Se perfila una "utopía racionalista" en la que la "organización racional-capitalista del trabajo formalmente libre" 10 construye un proyecto civilizatorio que, en el sentido de estos supuestos lógico-históricos, tendría un punto de inflexión en "1989", año simbólico de la "caída del muro de Berlín", representativa del bloque socialista como contrapeso histórico

\footnotetext{
${ }^{5}$ Gastón Bachelard, La formación del espiritu cientifico, México, Siglo XXI, 2003, p. 9.

6 Immanuel Kant, Critica de la razón pura, Buenos Aires, Losada, 2003, p.184.

${ }^{7}$ Max Horkheimer; Theodor W Adorno, Dialéctica de la ilustración, Madrid, Trotta, 1998, 136-140.

8 Werner Sombard, Der moderne Kapitalismus, Leipzig, Verlag von Duncker \& Humbolt, 1902.

${ }^{9}$ Cfr. F. Hegel, La fenomenología del espiritu, México, FCE, 1985, p. 249.

${ }^{10}$ Cfr. Max Weber, La ética protestante y el espiritu del capitalismo, México, Colofón, 1999, pp. 16-26.
} 
de la modernidad capitalista. De ahí se daría paso a un cuarto y último período, el que transitamos hacia modos de capitalismo histórico (por-conocer).

En la periodización que se perfila desde el pensamiento de Heidegger, todo comienza desde Parménides, a quien le es atribuida la identidad entre el "ser" y el "pensar", quien afirmaba: "es en efecto ser", afirmación que para Heidegger es digna de meditarse y que se encuentra muy cerca de la afirmación según la cual "ser es también pensar". ${ }^{11}$ Idea que lo acompañaría toda su vida distanciándose de manera fundamental de las formas de concepción del mundo que para él resultan, también, metafísicas, independientemente de dónde el pensador se coloque o fundamente su discurso: del "lado del sujeto" o "del objeto", el hecho mismo de pensar de manera "dual" (bajo el esquema sujeto-objeto: S-O) constituye un pensamiento metafísico. Por lo que para él el materialismo de Marx y la teoría de Nietzsche son, por ello, también metafísica: una "metafísica invertida"12, un "olvido del ser" que se alejó de un pensar originario el cual transitó por un proceso de cambio y transformación a través de la recepción latina (durante toda la dominación romana) que se consumó en la visión cartesiana de la relación esencial en la que confundió el "ser" con "el ente" y que toda la civilización occidental se ha encargado de edificar bajo un "olvido fundamental" confundiendo la unicidad del pensar y el ser. Para Heidegger no cabe la distinción entre sujeto y objeto, esa separación es ajena a su "pensamiento". Por lo que, entonces -según ello-, existe un primer período del pensar originario que comienza con Parménides (siglo VI a.n.e.) y termina en la decadencia de la Grecia clásica con el propio Aristóteles (siglo IV a.n.e.), cuando empleó el concepto de "physis" también en el sentido de "lo que se tiene enfrente" como Natura, como "objeto". ${ }^{13}$ De ahí se gestaría una transformación del pensar griego conformando un período transicional marcado por la etapa cartesiana en el siglo XVII, misma que daría paso al tercer período llamado por él la "época de la imagen del mundo", la "modernidad" (Neuzeit).

Cabe preguntarse entonces: ¿cuáles serán hoy los criterios que deben regir las consideraciones referenciales de una periodización histórica y de las nuevas formas del quehacer científico? ¿Debemos seguir la trayectoria hasta ahora dominante de considerar la física y la matemática bajo la idea de que son ciencias aparentemente "neutrales"? ¿Debemos conservar los referentes filosóficos bajo la idea de que es a través de esos ejes generales de referencia -la razón y la verdad-a partir de los cuales se construye toda argumentación ideológica y política muy a pesar de las posibles manipulaciones hegemónicas y sistémicas? ¿Debe partirse de los criterios de las ciencias de la naturaleza caracterizados por los avances en el conocimiento del genoma humano y el daño al medio ambiente con sus implicaciones ético-biológicas bajo nuevas "neutralidades"?

\section{La "condición posmoderna" y el reacomodo paradigmático de la labor científica}

Con el colapso del "socialismo real" (1989-1991), un tipo de socialismo "apócrifo", culminó una etapa de confirmación acerca de la imposibilidad de un camino civilizatorio inmediato distinto al avizorado en el último cuarto del siglo XX. Sin significar esto la confirmación del fracaso total de esta vía de construcción social, se pusieron en tela de juicio los principios teóricos y prácticos que le sirvieron como fundamento (el "marxismo", edificado metodológicamente sobre los principios del materialismo histórico y la dialéctica materialista), se abrió paso a los ya existentes y se abrió la posibilidad de dar paso a nuevas opciones de pensamiento. Se dejó el camino libre, entonces, a una etapa del capitalismo caracterizada por la "apertura": el liberalismo, que en economía pronto se travistió sobre una forma nueva, el "neoliberalismo". Esta nueva forma se arropó, a su vez, bajo una nueva "actitud social": la "incredulidad

11 Martin Heidegger, "Carta sobre el humanismo", en Hitos, Madrid, Alianza, 2000, p. 275.

12 Ibid., p. 276.

${ }^{13}$ Heidegger, "Sobre la esencia y el concepto de [physis]. Aristóteles, Física B, 1 (1939)”, en op. cit., pp. 199-249. 
en los metarrelatos", es decir, la incredulidad en los "paraísos terrenales" que ofrecieron los discursos de ideologías religiosas de toda índole y las ideologías políticas fracasadas hasta antes de la vuelta de siglo. Esto es lo que nos deja ver el rostro enjuto de lo que se ha dado por llamar "la condición posmoderna": una crisis generalizada de los "paradigmas" pero -como veremos- impregnado de un conjunto de estigmas heredados de la racionalidad imperante durante los últimos dos siglos: el "proyecto matemático de la naturaleza", la "técnica maquinista", la "razón instrumental", y, en el ámbito epistemológico, el empirismo y el positivismo revestidos de la "teoría de sistemas" ("complejos") y del "paradigma cibernético".

\section{A. El talante de la ciencia y la investigación en la "condición posmoderna"}

Empleamos la idea de "condición posmoderna"14 en el sentido inicial, el de una actitud de incredulidad hacia toda filosofía, ciencia, metodología, "ética" o ideología impositiva o hegemónica. Pero no aceptamos la idea, nada afortunada, de la "posmodernidad" ni bajo la forma de época dejada atrás, "superada" 15 , ni como el conjunto de características clasificatorias a manera de taxonomía de arquetipos estilísticos de procesos sociosemióticos propios del caos estético y el desencanto, ${ }^{16}$ las cuales es imposible de no ser percibidas (las manifestaciones surgen por doquier y "ahí están" pero de ningún modo en el sentido de época-histórica bajo el supuesto de haber arribado a una etapa "poscapitalista".

No obstante los rasgos aducidos por Lyotard a las sociedades avanzadas, no dejan de ser los espejos del futuro de las sociedades "atrasadas" contemporáneas en proceso de globalización: en la economía: el empleo de formas nuevas de circulación de capitales como complemento del liberalismo económico avanzado (la competitividad); en la administración: la operatividad creciente bajo un criterio tecnológico, menos homología de los expertos y más paralogía de los inventores, correlación "eficientista" de protecciónconducción-planificación; la clase dirigente la constituye la nueva clase de "tomadores de decisión"; se busca una disminución de funciones de regulación (conversión de los administradores en autómatas); en las relaciones sociales: se asumen los lazos sociales bajo modalidades y perspectivas "modernizantes", partiendo menos de una antropología de corte "newtoniana" que de una "pragmática de las partículas lingüísticas", se da un cambio de estatuto en la concepción de la colectividad pasando del estudio de las sociedades (edad postindustrial) a la inclusión de la "diversidad cultural" (edad "postmoderna"), y en su consideración acerca del individuo existe un desuso de la formación del espíritu (Bildung); la vida social como formas de automatización de lo social a través de "redes flexibles de juegos"; en política: el estado es un factor de opacidad y de ruido sesgándose la participación de los políticos como gestores de las demandas sociales; en ciencia: la investigación de la genética se convierte en la nueva ejemplaridad tomando como referente el "paradigma cibernético"; el saber se convierte en una mercancía informacional adquiriendo el carácter de potencia productiva cuyo cúmulo de información es dirigida por "expertos", en ella el saber científico, es tan solo un modo de saber, ya no dominante, basado más en la fonología y los bancos de datos, su producción transita de la circulación de hombres al de sonido e imágenes, en ello se manifiesta la oposición / conflicto entre el saber científico y el "narrativo" (legitimación de lo científico y oposición con lo ético-político: desde "Occidente"); el nuevo paradigma teórico y material de la sociedad ya no es el de organismo vivo sino sujeto "cibernético" en todo ello están presentes aquellas manipulación de la verdad unitaria y totalizadora, que se presta a una práctica unitaria y totalizante de los gerentes del sistema; no desaparecen, sino por el contrario se mantienen los dos tipos de saber ya existentes: i) el positivista (técnico-utilitario), y ii) el crítico (reflexivo / hermenéutico; la ciencia se reafirma como el "refuerzo de las capacidades productivas"; la ciencia "posmoderna" adquiere el talante de "investigación de inestabilidades"; en el lenguaje: predomina la tendencia a la deslegitimación de los grandes relatos con el menosprecio del discurso especulativo y emancipatorio asumiéndose una pragmática del saber narrativo a través de los juegos del lenguaje como método) ${ }^{17}$.

\footnotetext{
${ }^{14}$ Cfr. Jean F. Lyotard, La condición posmoderna, Madrid, Cátedra, 1998.

${ }_{15}$ Cfr. Gianni Vattimo, En torno a la posmodernidad, Colombia, Anthropos, 1994.

${ }_{16}$ Cfr. David Harvey, La condición de la posmodernidad, Buenos Aires, Amorrortu, 1998.

${ }_{17}$ Cfr., Lyotard, op. cit.
} 
Destacamos un señalamiento especialmente importante que vincula ciencia y producción, esto es, ciencia y economía: "la ciencia se reafirma como el refuerzo de las capacidades productivas", y aquella otra que destaca que existen dos tipos de saber, el positivista y el crítico, de ello depende no solo todo el trabajo teórico y metodológico sino toda la práctica investigativa predominante de la labor científica de nuestros días, a la que volveremos en un apartado posterior para cerrar este conjunto de reflexiones no sin antes revisar otros aspectos nada superficiales.

\section{B. Permanencia de las condiciones sistémicas estructurales de la "ciencia normal"}

Para establecer un juicio referido a las condiciones y al fundamento de la praxis que predomina en el ámbito de la investigación científica, podríamos partir de un análisis de la naturaleza de la ciencia misma, de su statu quo por el que transita, así como de su modo de proceder, aspectos que cualifican, de acuerdo con Heidegger, no solo un modo de proceder y un conjunto de causalidades encriptadas u ocultas, mismas que deben ser desencubiertas tantas veces como se vuelva necesario. Exaltamos aquí que ellas son la mímesis de una época: la modernidad capitalista en su período actial. Statu quo y causalidades ocultas hacen de su encriptamiento una "ciencia normal". Un aspecto que se vuelve necesario descodificar y desencubrir hasta donde nos sea posible.

Empleamos la expresión de "ciencia normal” en el sentido de Thomas S. Kuhn, como una expresión sintomática que denota el statu quo de la labor científica del que hablamos, a saber:

'Ciencia normal' significa investigación basada firmemente en una o más realizaciones científicas pasadas, realizaciones que alguna comunidad científica particular reconoce, durante cierto tiempo, como fundamento para su práctica posterior.

La ciencia normal, la actividad en que, inevitablemente, la mayoría de los científicos consumen todo su tiempo, se predica suponiendo que la comunidad científica sabe cómo es el mundo. ${ }^{18}$

A partir de lo anterior se puede destacar que existe un proceso de desarrollo científico que se caracteriza por un tipo de práctica "ordinaria" a través del cual una comunidad científica elabora su investigación en condiciones a su vez "ordinarias", en las que dicha comunidad "sabe cómo es el mundo", a las que se suman un conjunto de modos de proceder (métodos) y referentes trazados, que rigen la teoría y la práctica de los científicos, aspectos que Kuhn agrupa en lo que llama "paradigmas". Cuando estos "paradigmas" o construcciones conceptuales o métodos ya no dan cuenta de la realidad, entonces se transita por un período que Kuhn llama de "revolución científica", transcurrida en condiciones" extraordinarias y a la que deberá adecuarse de manera también "extraordinaria" una nueva "concepción del mundo", adecuación a la que deberá seguir, por tanto, un "cambio de paradigmas" y atravesar por un proceso cognitivo que le permita ver la naturaleza de tales cambios: "Lo que un hombre ve depende tanto de lo que mira como de la experiencia visual y conceptual previa lo ha preparado a ver. En ausencia de esa preparación sólo puede haber, en opinión de William James, 'una confusión floreciente'.”19

Bajo la perspectiva que hemos esbozado anteriormente resulta interesante emplear las ideas de Kuhn para preguntarse: ¿cuál es esa experiencia "visual” y -sobre todo- "conceptual" que hemos acumulado a través de las instituciones científicas de que disponemos?, ¿cuál la naturaleza epistemológica de la teoría y el instrumental metodológico que se forja en ellas y por ellas? Pero, sobre todo, ¿cómo se favorece el distanciamiento de paradigmas heredados por prácticas y enfoques anquilosados desde siglos atrás? ¿Cuáles son esas prácticas, cuáles esos enfoques y cuál la posibilidad real de salir de ellos? De no salir bien librados de tales problemáticas, en efecto, solo estaremos destinados a ser portadores de una muy buena,

18 Kuhn, T. S, La estructura de las revoluciones cientificas, México, FCE, 1986, p. 33, 26.

${ }^{19}$ Ibid., p. 26 y 179. 
abigarrada y a la vez inconciente, en el mejor de los casos, "confusión floreciente", en el peor de ellos, ni siquiera seríamos capaces de visualizarlos.

Destacaremos algunos rasgos estructurales que permean la ciencia y los modos en que ella se genera, uno de carácter estructural-civilizatorio y otro sistémico: "la ciencia de la modernidad" el primero y la razón instrumental, el segundo.

Durante el período que transitamos somos testigos de un conjunto de fenómenos acompañados de sus respectivas causalidades encriptadas que, por ello mismo, no son por todos percibidas dado su estado de “ocultamiento". Toda vez que no 'aparecen ante los ojos', subyacen en la praxis teórico-empírica de lo que -empleando la expresión de Kuhn- constituye la "ciencia normal". Estas causalidades que permean la dimensión epistemológica son su carácter y modalidad "modernista"; la hipóstasis 'matematizadora' del pensamiento moderno; su "razón instrumental"; y -de acuerdo con Kuhn-, su "confusión floreciente", en torno a la disciplinariedad (uni / inter / multi / trans / disciplinariedad) de la praxis científica.

a) La modalidad "modernista" de la praxis cientifica, va mucho más allá de un estilo o un modo de "hacer ciencia", fue expuesta claramente por Heidegger y los teóricos de la Escuela de Francfort, Horkheimer y Adorno, en el contexto de una caracterización sumamente radical de lo que identifica como "fenómenos esenciales de la 'Edad Moderna' (Neuzeit), la Modernidad. Esta época podría adjetivarse como "cartesiana", dado el consenso general del pensamiento contemporáneo acerca del hito que representa Descartes para la ciencia y la razón, la filosofía y el discurso filosófico sobre ambas. ${ }^{20}$

Según M. Heidegger, los fenómenos que caracterizan de manera fundamental la modernidad son: 1) La ciencia; 2) La técnica maquinista; 3) La colocación del arte en el campo visual de la estética; 4) La concepción y realización del obrar humano como cultura, y 5) La desdeificación (Entgötterung). ${ }^{21}$

Es destacable su análisis sobre el papel que guarda la investigación en la construcción de la ciencia moderna, al grado tal de afirmar: la esencia de la ciencia es la investigación, una cierta labor en la que el 'conocer' se instala como 'proceso' en un determinado dominio del 'ente', la 'naturaleza' o la 'historia'. El 'proceso' no queda definido por el modo de proceder (el 'método') sino por la actividad que consiste en 'abrir un campo' (campo de 'objetos') en el que se 'esboza un plano' y se determina el 'rigor' para garantizar el proceder dentro del 'dominio de ser' de su 'campo de objetos'. El 'rigor' con el que procede 'la investigación' es la combinación 'trazada de antemano' en el 'esbozo' y en la cual se expresa el 'modo' en que el 'proceso cognitivo' habrá de combinarse con el 'campo abierto'. Este 'esbozo' -que en la terminología de nuestro medio académico podríamos traducirlo como proyecto-, este 'trazo de antemano', 'trazo anticipado' o 'trazo previo' es un encuentro de la razón con el substrato matemático que el hombre proyecta sobre la naturaleza con la intención de conocerla, puesta de manifiesto en el proceder investigativo de la ciencia pero que va más allá de ella:

[Tà matèmata] significa para los griegos aquello que el hombre ha conocido de antemano [voraus kennt] al examinar lo existente y al tratar con las cosas: de los cuerpos lo corpóreo, de las plantas lo vegetal, de los animales lo animal, del hombre lo humano. A esto ya conocido, es decir, matemático, pertenecen además de lo citado, también los números. Cuando sobre la mesa hallamos tres manzanas, conocemos que hay tres. Pero ya conocemos el número tres, la triada. Esto quiere decir: el número es algo matemático. Solamente porque los números constituyen por así decir lo siempre ya conocido [Immer-schon-Bekannte], y por tanto, lo más conocido [das Bekannteste] de las matemáticas, por lo que lo matemático quedó reservado como denominación de lo numérico. Pero esto no quiere decir en absoluto que la esencia de lo matemático esté determinado por lo numérico. ${ }^{22}$

\footnotetext{
${ }^{20}$ En este sentido coincidimos con las consideraciones de partida de Bachelard en el sentido de que "la primera tarea en la que se funda el 'espíritu científico' consistió en tornar geométrica la representación”. Bachelard, op. cit., p. 7.

21 Martin Heidegger, “Die Zeit des Weltbildes”, en Hol₹wege, Frankfurt am Main, Vittorio Klostermann, 1980.

22 Ibid, pp. 73-74.
} 
Lo matemático, el trazo previo, es lo que se expresa con el acto de elaboración de un proyecto en el que el sujeto se coloca en su camino, entra en su dimensión. Esto se logra cuando, mediante el proceso, el 'campo esbozado' es capaz de colocarse en el plano del 'objeto' cuando es desmembrado en toda la 'multiplicidad de sus sustratos' y 'ramificaciones' mediante la observación minuciosa de los 'hechos'. Solo en el campo visual de la 'regla' y de la 'ley' los 'hechos' llegan a ser claros como 'hechos' que son, puesto que con ellas sus 'variaciones' son capaces de ser "detenidas" -artificialmente- no obstante su estado de 'movimiento': "la ley es lo constante de la variación en la necesidad de su transcurso". La 'explicación' de los 'hechos' solo se consigue a través de la investigación misma pero la ciencia de la naturaleza no se convierte en investigación gracias al experimento sino a la inversa, el experimento es posible "allí y solamente allí donde el conocimiento de la naturaleza se ha transformado en investigación" 23 . Las ciencias, sean estas de la naturaleza o del espíritu, sólo son 'legitimadas' y adquieren un debido 'prestigio' cuando son cultivadas en una 'institución'. En tal proceso, la figura del 'sabio' desaparece para ser reemplazada por la del 'investigador', un personaje que ya no necesita una biblioteca para estar informado, ahora esto lo logra mediante su asistencia a 'juntas' y 'congresos'. Finalmente, toda 'ciencia', en tanto que 'investigación' se funda en el esbozo de un 'campo de objetos delimitado’ y, por lo tanto, es necesariamente 'ciencia especial'. Así, la 'especialización' no es una consecuencia sino la 'razón del progreso' de toda investigación.

En Heidegger existen, en verdad, un conjunto de ideas que ponen de manifiesto lo que él denomina el "proyecto matemático de la naturaleza", que no es sino la acción humana considerada en su conjunto, como "Occidente" extendido ya a nivel planetario, quien mediante el uso irracional de la técnica y el pensamiento calculista amenazan y ponen en peligro permanente a la naturaleza toda, convirtiéndola en mero "reservorio" (lo "Ge-stell")24, un "armatoste" o mera "estantería" ("recurso" natural) de la que se pueden extraer los "enseres" al antojo y necesidad humanas. Se trata pues, de una salida a la luz pública de "fuerzas ocultas" que operan en lo más profundo de la "razón" y que proviene de la "noche de los tiempos" en que el logos, (la "razón”) construyó la dualidad sujeto-objeto, dando paso a un conflicto civilizatorio que permanece en el obrar del hombre contemporáneo.

b) La "razón instrumental" constituye un campo problemático ineludible e imprescindible cuando se explora seriamente el mundo de las causalidades que configuran la gran mayoría de los procesos de generación de conocimiento científico y se exploran las relaciones fundamentales implicadas en los campos temáticos generados en los "puentes epistemológicos" entre las ciencias naturales, las ciencias sociales y los fundamentos éticos sobre los cuales se levantan sus implicaciones. Consideramos que sus puntos de partida son dos supuestos-clave a través de los cuales se hace posible su validez y la trascendencia de su aceptación: el primero consiste en lo que podríamos llamar un "refrendo" que -en verdad- es un principio, el de "razón", un punto de "partida", puesto que no se trata de un invento de la "ilustración" del siglo XVIII sino de una consideración que viene desde los tiempos presocráticos de Heráclito quien señala por primera vez el carácter universal de la razón. Lo que es digno de destacarse aquí es que no siempre ha prevalecido esta facultad humana en los asuntos políticos decisorios y definitorios del progreso social y de los asuntos públicos (aspecto que aún en nuestros días sería amplia y frecuentemente dudoso) como en el caso del Medioevo, en el que dominó la fe, o como en la Antigüedad lo fue la fuerz $a^{25}$ constituida como un estatuto hegemónico muchas veces no declarado de las relaciones entre culturas y civilizaciones tomadas todas ellas en su conjunto. En segundo lugar, la consideración de una "razón instrumental" tiene como supuesto que en la relación fundamental de todas las acciones humanas, regidas por la relación fin-medio, el "medio" (la base tecnológica de la sociedad; las fuerzas productivas en su conjunto) ha suplantado al "fin" (la socialidad, la comunidad, el bienestar, el "buen

23 Martin Heidegger, "La época de la imagen del mundo”, en Sendas perdidas, Buenos Aires, Losada, 1979, p. 71.

24 Martin Heidegger, "La pregunta por la técnica", en Conferencias y articulos, Barcelona, Serbal, 1994.

25 Engels-Marx, La ideología alemana, Montevideo, Ediciones Pueblos Unidos, 1974, p.75. 
vivir", la solidaridad, la libertad, la fraternidad, el amor al (y a lo) otro, la felicidad humana, en el supuesto que esto se ha planteado y buscado, de facto. Se trata de una deformación de la acción humana en su conjunto en la que el campo instrumental se encuentra sesgado hacia el lado "malo" (destructivo) de su uso.

La crítica de la razón instrumental fue elaborada en los primeros años posteriores al holocausto como consecuencia de la Segunda Guerra Mundial. Fue asumida por buena parte de los pensadores de la Escuela de Francfort (Horkheimer, Adorno, Benjamin, Marcuse, Habermas y Schmidt, principalmente) y, lejos de convertirse en una denuncia más que justificada del uso destructivo que "el hombre" es capaz de hacer hacia los "otros hombres", buscó los fundamentos desde los cuales una parte del género humano (y no todo él) -los "dueños y decididores del uso de la tecnología"- crea las condiciones para que el campo instrumental en su conjunto se ponga al servicio del capital y se supedite mediante el dominio político a un tipo de fenómenos de la naturaleza no-natural ("transnaturalizada") 26: la razón instrumental. ${ }^{27}$

Podemos revisar la historia de esta problemática para buscar la consistencia de las conexiones básicas entre la razón en general, la razón "instrumental" y la labor científica. Para ello partimos de una primera idea que destaca el papel fundamental de la razón. Marcuse ${ }^{28}$ la expresa del siguiente modo:

En la ecuación Razón = Verdad $=$ Realidad, que une los mundos subjetivo y objetivo en una unidad antagónica, la razón es el poder subversivo, el 'poder de lo negativo' que establece, como razón teórica y práctica, la verdad para los hombres y las cosas; o sea, las condiciones dentro de las que los hombres y las cosas llegan a ser lo que son realmente. El intento de demostrar que esta verdad teórica y práctica no es una condición subjetiva sino objetiva fue la preocupación original del pensamiento occidental y el origen de la lógica, no en el sentido de una disciplina especial de la filosofía, sino como la forma de pensamiento apropiada para aprehender lo real como racional.

El verdadero razonamiento, la lógica, revela y expresa aquello que realmente es, separado de aquello que parece ser (real). Y gracias a esta ecuación entre verdad y ser (real), la verdad es un valor, porque ser es mejor que no-ser. Lo último es simplemente la nada; es una potencialidad y una amenaza al ser: la destrucción. La

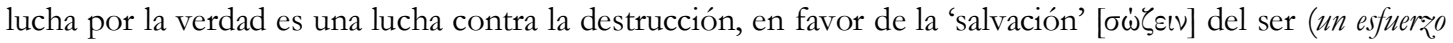
que parece ser en si mismo destructivo si ataca una realidad establecida como 'falsa': Sócrates contra la ciudad-estado ateniense). En tanto que la lucha por la verdad 'salva' a la realidad de la destrucción, la verdad empeña y compromete la existencia humana. Es el proyecto esencialmente humano. Si el hombre ha aprendido a ver y saber lo que realmente es, actuará de acuerdo con la verdad. La epistemología es en sí misma ética, y la ética es epistemología.

Actualmente, a más de cincuenta años de haberse escrito estas ideas ${ }^{29}$, se podría hacer un recuento de las formas de la "razón" expresadas hasta hoy (la razón pura; la razón práctica; la razón instrumental; la razón jurídica; la razón poética; la razón cínica; etc., etc., -y nosotros ponemos a consideración aquí la idea de una "razón urbanística"), pero caemos en la cuenta de los puntos de partida resaltados por Marcuse y la Escuela de Francfort hace medio siglo: la razón y la realidad constituyen los elementos antagónicos de una búsqueda de la verdad, la más humana de las formas en que el hombre puede buscarse a sí mismo. Subjetivamente, lo puede hacer a través de los distintos discursos "ideológicos", entendida la "ideología" en el peor de los sentidos, como una "falsa conciencia", como la religión, el mito, el arte, la poesía, etcétera, que han caracterizado ese lado del "corazón" que se abre como "esperanza" y que alumbra un tipo de civilización "no occidental". Objetivamente, la razón busca la "verdad" haciendo uso de la ciencia y, cada vez en menor medida y con mayor desuso, la filosofía.

En la cita anterior, Marcuse emplea la expresión "poder de lo negativo" no en el sentido de un "fuerza "negativa" sino en el sentido de que la realidad existe en un doble plano: un plano positivo, que integra

\footnotetext{
${ }^{26}$ Cfr. Bolívar Echeverría, Definición de la cultura, México, UNAM-Itaca, 2010, pp. 127-145.

27 Jürgen Habermas, Ciencia y técnica como “ideología”, México, Red Editorial Iberoamericana, 1996, p. 55.

28 Herbert Marcuse, El hombre unidimensional, México, Planeta/Artemisa, 1985, pp. 151-153.

${ }^{29}$ El hombre unidimensional fue escrito en 1964.
} 
todo lo que tenemos "frente a los ojos" y que es perceptible para nuestros sentidos, y otro plano negativo, al que se puede tener acceso sólo con la capacidad que consiste en abstraer lo que se tiene "ante los ojos" mediante esta facultad que en algún tiempo de la historia griega clásica gozó de gran prestigio: la especulación, una facultad netamente humana de búsqueda de la verdad mediante el pensamiento, aspecto que propició el surgimiento de la filosofía. ${ }^{30}$ Negativo no es de ningún modo una intención destructiva, un mal uso de las capacidades humanas o algún tipo de "poder infernal" infructífero para el conocimiento de la verdad, sino el uso de la razón en ese substrato o plano suyo al que se arriba mediante la búsqueda de las esencialidades (que no se encuentran "frente a los ojos") y por lo tanto no son, estrictamente hablando fenómenos. La idea de que "la verdad está en los hechos" es un sofisma, pues en verdad, si la esencia (de la verdad) coincidiera con la apariencia (el fenómeno) la ciencia carecería de sentido (Marx). El desdén por el substrato negativo de la razón, es decir, por aquella facultad de búsqueda de la verdad mediante el pensamiento, ha conducido al dominio técnico (maquinaria y gran industria productivista) y tecnológico (ciencia aplicada a la ciencia misma y a la producción) hacia el monopolio de la verdad por el empirismo y el llamado "positivismo lógico" (método "positivista"; verdad "objetiva" -positiva-; ciencias positivas: derecho positivo, economía positiva / "racional", música "racional”, etc., etc.). Esto dio lugar a la afirmación de Heidegger que "la ciencia no piensa, sólo explica"31, lo cual es cabalmente entendido si se pone en el plano de las causalidades de búsqueda de la verdad y se distingue esta doble presencia de la realidad mediante el pensamiento, la relación dialéctica (el movimiento) entre los polos objetivo y subjetivo de la razón. Este extravío se ha propagado silenciosamente en los ámbitos de la labor científica teórica y práctica, la cual será necesario revisar en sus fundamentos, no sin antes redondear algunas ideas en torno a las implicaciones de esta "crisis", su dominio ideológico y sus secuelas investigativas:

La crisis contemporánea de la razón radica fundamentalmente en el hecho de que, llegando en su evolución a determinada etapa, el pensamiento o bien perdió por completo la capacidad de concebir tal objetividad, o bien comenzó a combatirla como un espejismo. Este proceso vino poco a poco a afectar hasta el contenido objetivo de todo concepto racional. Finalmente no hay realidad singular alguna que pueda aparecer como racional per se; vaciados de su contenido, todos los conceptos fundamentales se han convertido en meras cáscaras formales ${ }^{32}$.

Hablar, entonces, de una "razón" en esta perspectiva resulta una suerte de extravío en el que existe un cercenamiento de una parte fundamental de ella, la que percibe el mundo, la realidad, sustancial y esencialmente, muy a pesar de la invocación de los "análisis cualitativos" del "objeto de estudio" respectivo, cosa que, dada la carencia de búsqueda de las múltiples determinaciones y relaciones, se convierte en mera aspiración.

La "razón urbanística" es una modalidad de la "razón instrumental". El rasgo fundamental de ella es la cosificación ${ }^{33}$ de los aspectos teleológicos de la vida humana, la socialización del mundo de la vida, mutada en la pura instrumentalidad de los fines, una inversión que transforma los fines en medios y viceversa, los medios en psendo fines. De este modo, la "razón urbanística" ha olvidado por completo que su carácter teleológico, su fin último, es la socialidad y no la mera aglomeración de sujetos. Su destino es el destino del campo instrumental de la ciudad, y, con ello y por ello, el destino de la técnica. La "cosmovisión" que construye es la obnubilación de su mirada por la luminosidad de la civilización moderna en detrimento de la naturaleza y del resto de las expresiones del mundo viviente, bajo el sino de

\footnotetext{
${ }^{30}$ De ahí que Bachelard - en una coincidencia no declarada con el materialismo de Marx- le atribuya el rango de ley, la Ley de los tres estados para el espíritu cientifico: $1^{\circ}$. El estado concreto; $2^{\circ}$. El estado concreto-abstracto; $3^{\circ}$. El estado abstracto. Cfr., Bachelard, op. cit., p. 11.

31 Martin Heidegger, “¿Qué quiere decir pensar?”, en Conferencias y artículos, Barcelona, Serbal, 1994, p. 117.

32 Horkheimer Max, Crítica de la razón instrumental, Madrid, Trotta, 2002, p. 48.

33 Georgy Lukács, Historia y conciencia de clase, México, Grijalbo, 1969, p.95.
} 
la arrogancia, la autosuficiencia y el desprecio por todo aquello que no provenga de la 'nueva 'naturaleza' artificial", la del asfalto y la de la vida sintético-plástica. Un rasgo de su identidad que trae consigo la potencialización totalizante del "urbanocentrismo" 34 y la negligibilidad ${ }^{35}$ de lo que acontezca fuera de sus límites: su pretensión de ya no depender más del campo, y la "devaluación de la naturaleza" 36 -la inyección de valor, el valor agregado, es preferible a las materias primas 'naturales', poco útiles en el momento de la tasación de la ganancia-. El paraíso en el que encuentra su temporalidad ideal es la modernidad pseudoconcreta ${ }^{37}$ y su administrador fundamental es el capitalismo. Por ello las leyes y principios fundamentales que la rigen son las pertenecientes a las cosas antes que las pertenecientes a la socialidad de sus creadores. Es por eso comprensible que el lenguaje de las cosas domine al lenguaje de los humanos y a la enajenación de éste le sea impuesto el dominio de aquél 38 : para la "razón urbanística" es prioritario lo funcionalmente útil que lo bello, sacrificándolo, incluso, ante lo prosaico. Lo funcionalmente útil debe tender a ser "grato y "bonito" mientras que lo bello y lo poético es expulsado de la ciudad"39.

A la "razón urbanística" le sienta bien el lenguaje y el fundamento de la ciencias positivistas porque su lógica es la lógica de las cosas cuantificables demostrables sólo en la medida en que pueden ser reproducibles como "cosas del mundo urbano" (cosas de la ciudad), propias de un lenguaje, por tanto, cosificado $^{40}$, discernible, cuantificable y demostrable desde la ciudad, aun cuando la ciudad y lo urbano no sean lo mismo pero para ella es tendencialmente "igual": la urbanización completa del mundo es su futuro cada vez más próximo y el derecho a la civilización es el derecho más "progresista" que la vida urbana (racionalmente) haya podido formular en tanto que "derecho a la ciudad". El fundamento de toda predicción futura es el discurso positivista de la previsión a través de la planificación urbanocentrista basada en la calculabilidad del mundo de la vida como mero "recurso": "capital social", comercial, financiero, "humano", etc.).

La "razón urbanística" es, pues, un modo de la razón instrumental. Pero ni la razón instrumental es solo "razón urbanística", ni ésta, pura sublimación de aquella. El elemento fundamental que las diferencia, la esencialidad que las separa cualitativamente, es la materia de la que están hechas: su habitabilidad social.

Así, elaborar una crítica de la 'razón urbanística' se cimenta sobre los fundamentos de la relación espaciotiempo sociales, en general, aspectos tales como la concepción óntico-ontológica del espacio social, la naturalidad-transnaturalidad de la relación hombre-naturaleza, en un primer nivel de argumentación, el más abstracto dado que se trata del plano más general de la existencia humana. Se prepara entonces el paso a un segundo nivel de la argumentación con lo que se podría denominar la "ontogénesis de la ciudad" abordando, a su vez, el plano de la oposición campo-ciudad en los márgenes de su transhistoricidad. Un tercer nivel de argumentación está integrado por los fundamentos sistémicos de la crítica de la ciudad y del espacio social capitalista en general, mismo que da origen a las dimensiones antropológicas de la cultura modernas, que se engloban en la multidimensionalidad de los fenómenos de la enajenación de la socialidad de los individuos que habitan las ciudades y megaconglomerados de los asentamientos urbanos contemporáneos. Se cuenta, entonces, con los elementos suficientes en la construcción argumental y crítica para el arribo a un "cuarto nivel" -si es que nos permitimos esta artificialidad enteramente didáctica de la relación sujeto-objeto que denominamos aquí "ciudad"integrado por tres esferas fundamentales de la vida social humana, a saber, el de las representaciones, el de la presencia potencial de la revolución social y el del plano de la utopía, correspondientes respectivamente a la dimensión semiótica de la vida urbana en las grandes metrópolis; la dimensión postaurática del habitar poético, aspecto en el que Walter Benjamin constituye una voz aún hoy poco

\footnotetext{
34 Jorge Gasca, La ciudad: pensamiento crítico y teoría, México, IPN, 2005, pp.195-196.

35 Jorge Gasca, Pensar la ciudad. Entre ontología y hombre, México, IPN, 2007, pp. 282-283.

36 Bolívar Echeverría, Modelos elementales de la oposición campo-ciudad, México, UNAM-Itaca, 2013, p.82

${ }^{37}$ Karel Kosík, Dialéctica de lo concreto, México, Grijalbo, 1976, p.27.

38 Engels-Marx, Cuadernos de parís, México, Era, 1980, p.153. (tr. Bolívar Echeverría)

39 Cfr., Karel Kosík, "La ciudad y lo poético", Rev. Nexos, Febrero, 1998.

40 Cfr., Paolo Cesar Pereyra, "La ciudad: sobre la importancia de nuevos medios para hablar y pensar las ciudades", en Revista Mundo Siglo XXI, Núm. 9, Verano de 2007, Centro de Investigaciones Económicas, Administrativas y Sociales (CIECAS), México, IPN, 2007, pp. 69-80.
} 
escuchada ${ }^{41}$ y la existencia en ruptura (Bolívar Echeverría) en el espacio social; y lo que podríamos denominar la dimensión social de la utopía y la esperanza: las "urbanotopías". Pertenece a esta dimensión de la "racionalidad" todo el discurso de la planificación racional del desarrollo material y social. Una "crítica de la razón urbanística" presupone, pues, la identificación de las claves fundamentales para la caracterización de lo que denominamos la "razón urbanística" y que permitiría posteriormente su "crítica".

c) La "confusión floreciente" en torno a la disciplinariedad: confusión entre ciencia y disciplina. Es una amplia y asombrosa ambigüedad que circula por doquier en el ámbito docente e investigativo de la labor científica y nos muestra cuan irreflexivo es el pragmatismo imperante que ha perdido "la brújula" en toda referencia de las implicaciones epistemológico-históricas. Surca no solamente el "orden administrativo" de los 'gerentes' de la labor científica, sino de la labor científica misma, traspasando hasta las supuestas salidas epistemológicas y metodológicas en los horizontes de esta labor. Nos referimos a la "confusión progresiva", o mejor sería decir, a la paulatina confusión que se ha gestado en la "ciencia normal" de los últimos dos siglos, difundida de manera silenciosa en las universidades e institutos de investigación y se manifiesta hoy en la llamada disciplinariedad (uni / inter / multi / trans / disciplinariedad) de la praxis científica. En esta confusión sobrevuela el "espíritu de la hiperespecialización técnica" proveniente de la ciencia y la técnica modernas que ya hemos analizado más atrás y que en este lugar de la exposición ponderaremos en sus implicaciones pragmáticas, revisando los principios en los que se sustenta.

En este punto de partida elemental se da lugar a establecer la cualificación de la(s) ciencia(s) y la(s) disciplina(s) desde la cual puede delinearse la posibilidad de ser captada esto que hemos llamado "espejismo" que en honor a la verdad es una gran confusión. Para reparar en ello nos permitiremos partir de una definición básica: la de ciencia.

Una ciencia generalmente se define del siguiente modo:

Ciencia (del latín scientia, de scire, saber) es la actividad humana productora de conocimiento científico. Aquella actividad cultural humana que tiene como objetivo la constitución y fundamentación de un cuerpo sistemático del saber [...] el conocimiento del que trata es un conocimiento racional, que se refiere al mundo material o naturaleza, cuyas regularidades quiere explicar y predecir, obtenido mediante un método experimental, del cual forman parte la observación, la experimentación y las inferencias de los hechos observados; es sistemático porque se organiza mediante hipótesis, leyes y teorías, y es un conocimiento objetivo y público, porque busca ser reconocido por todos como verdadero o, por lo menos, ser aceptado por consenso universal. ${ }^{42}$

De este tipo de definición parte la construcción del "mapa de las ciencias" divididas en tres grandes tipos: las ciencias formales (como la lógica y las matemáticas -teóricas), las ciencias naturales (biología, química, astronomía, la física, la geografía física), y las ciencias sociales o del espíritu (Rudolf Carnap).

Por otra parte, la idea de "disciplina” consiste, de acuerdo con Horkheimer en lo siguiente: "La expresión 'disciplina' designa las reglas codificadas en los manuales más avanzados y aplicados con éxito por los científicos en los laboratorios. Se trata, sin duda, de métodos asumidos altamente representativos típicos- de las ideas actualmente dominantes acerca de la objetividad científica...". 43

Se trata de "subdivisiones" de las ciencias que se crean para "mejor" y "mayor" "profesionalización" de quienes las estudian. De esta consideración general parte la elaboración de los "catálogos de profesiones" o "carreras" los cuales resultan sorprendentemente vastos. Tan solo un "botón de muestra" tomado al azar, desde luego, sería suficiente para notar que una ciencia es fragmentada para integrarse en "subdivisiones", mismas que pasan a ser -de ese modo- "disciplinas". Un ejemplo de cada uno de esos tres "tipos de ciencias" bastaría para clarificar esta vastedad: MATEMÁTICA (Álgebra, Análisis y Análisis

41 Walter Benjamin, La obra de arte en la época de su reproductibilidad técnica (Urtext), México, Itaca, 2003, pp. 46-48.

42 Herder, Diccionario de filosofía, Madrid, 2002.

${ }^{43}$ Horkheimer, op. cit., p. 100. 
Funcional, Estadística, Geometría, Métodos Numéricos y Computación, Probabilidad, Teoría de los Números, Topología, otras); GEOLOGÍA (Estratigrafía, Geohidrología, Geología Económica, Geología Marina, Geo-morfología, Geoquímica, Paleontología, Petrografía, Petrología, Sedimentología, Tectónica, otras); GEOGRAFÍA - una ciencia que contiene, a la vez, "porciones de naturaleza" y "porciones de sociedad”- (Geografía Económica, Geografía Física, Geografía Humana, otras).

Pero, en términos óntico-ontológicos: ¿qué hace el ser humano, la 'razón', cuando divide, subdivide, vuelve a subdividir, separa y clasifica de ese modo la "realidad", sea esta lógica (formal), natural, o social (espiritual)?

En primer lugar, la "razón" se "instrumentaliza" convirtiéndose en utensilio del acto del "conocer" erradicado de su substrato negativo, privándose de su capacidad activa en la articulación Razón = Verdad = Realidad, es decir, expulsa su potencialidad subjetiva de búsqueda de la verdad mediante el pensamiento. En segundo lugar, "cosifica" la Realidad (la naturaleza, la sociedad y el pensamiento) convirtiéndola en mero "objeto". La "objetualiza" en aras de una supuesta demostrabilidad de "hechos" tangibles y "objetivos" puestos por la naturaleza "ante los ojos" del "sujeto cognoscente" (en este caso, el que estudiamos, el científico-investigador) para explicar y predecir sus regularidades (calculabilidad de los hechos), obtenida mediante un método experimental, "del cual forman parte la observación, la experimentación y las inferencias de los hechos observados". En tercer lugar, al cercenamiento de la facultad del pensar activo de la razón y a la ya de por sí fragmentada visión parcelaria de la realidad a través de división en "campos del conocimiento". Le sigue la "hiperespecialización del saber", que no es sino la hiperfragmentación de esta "realidad", mediante el prurito de la "profesionalización". La "profesionalización" misma, a través de la subdivisión de las ciencias en "disciplinas", promueve de manera inconsciente la especialización que se estudia volviendo más competente al "profesional" pero privándolo de su capacidad de "pensar" las causalidades que articulan el todo orgánico de la realidad (la realidad como un todo, único). En cuarto lugar, mediante la visión hegemónica de los métodos "experimentales", pragmáticos y, en general, empiricos, se vuelve "positivo" todo el contenido de las ciencias, sesgándolas con el riesgo de una visión indiferente de la esfera de las causalidades, implicaciones y valores sociales no-destructivos de la humanización del mundo, aspecto que constituye el quinto elemento aquí destacado: la verdad como valor fundamental del conocimiento humano, de esto que llamamos rąón.

Esta suerte de "disección epistemológica", que lejos de significar una segmentación de las ciencias y de la realidad constituye una "fractura de la razón" que no hace sino manifestar las realidades y los retos que cualquier pensador, científico o ser humano en general tiene frente a sí cuando pretende "formularse" una explicación de su fracción de mundo o dar cuenta de la "tediosa apariencia de la diversidad"4t. Es más que evidente y cae por su propio peso, el hecho de que en el trabajo científico investigativo hablar de uni / inter / multi / trans / disciplinariedad no es una garantía de un diálogo entre ciencias por un hecho de partida: Ciencia $\neq$ Disciplina.

Algunos ejemplos palpables los observamos en el "campo de la medicina" (Biología humana: anatomía, neurología, cardiología, neumología, osteología, oncología, angiología, oftalmología, etc.) o de lo que se nombra "ingeniería civil" (Física y Matemáticas aplicadas a la construcción: hidráulica, geotecnia, topografía, "estructuras", etc.). Ninguno de los dos "campos" constituyen stricto sensu una ciencia, sino un cúmulo de disciplinas con bastante frecuencia inconexas entre sí muy a pesar de referirse al mismo "objeto de estudio": en la medicina, el hombre en su calidad de "sujeto individual" (singular: el "paciente"); en la "ingeniería civil", el ambiente antrópico (el espacio construido por el hombre con fines "civiles", es decir, "no-militares", "no-religiosos", o de cualquier otra índole, pero que sostenga la procuración del "bienestar" general de la materialidad social de uso colectivo o privado"). En ellas la relación entre ciencias es, en rigor, un mito.

En la práctica es sumamente improbable que un neumólogo, por ejemplo, que estudia los pulmones de un 'paciente' con enfisema pulmonar que ha fumado veinte, treinta o cuarenta cigarrillos por día durante

${ }^{44}$ GWF Hegel, La Fenomenología del espiritu, México, Fondo de Cultura Económica, 1985, p. 14. 
treinta de los cincuenta años que tenga de vida (en el supuesto de que siga vivo) realice él mismo los análisis de laboratorio oncológico o estudie las causas que orillaron a dicho individuo a llevar una vida hacia la autodestrucción de la salud de su organismo. La "profesionalización" o "especialización" (hiperespecialización) del médico, en el mejor de los casos, además del tratamiento radiológico, si fuera el caso, haría conducir al paciente en cuestión con un psicólogo que lo auxilie en la ardua tarea de "dejar el cigarro". El neumólogo no está facultado para dominar todas las disciplinas de la medicina, ni mucho menos la interconexión de "su ciencia" (toda la biología) con otras ciencias como la psicología, la sociología o la antropología que podrían dar cuenta de la conducta patológica del sujeto "enfermo". La medicina alópata moderna es una evidencia innegable de la metodología y la concepción "positivista" de la naturaleza.

En "ingeniería civil" es muy frecuente el hecho de la separación entre el "topógrafo", el "geotecnista", el "proyectista", el "estructurista" y el "constructor". Cabe, en primer lugar, preguntar: desde el punto de vista epistemológico ¿de qué científico hablamos cuando nos referimos a un "ingeniero civil" o un “experto en puentes"? ¿Hablamos acaso de un 'físico’? ¿Nos referimos a un matemático? ¿O acaso de un geólogo? En realidad nos referimos a un fisico-práctico ocupado en las labores de la construcción de puentes ${ }^{45}$. Pero se trata de un físico que socialmente se cualifica, gracias a su profesión (su "título" o "diploma") como "ingeniero", pero él mismo no se reconocería como un "científico" de esa rama de la ciencia. En este caso, el de la construcción de puentes -como en el de la medicina-, la interdependencia entre disciplinas es indiscutible, pero en ningún momento es garantía del dominio de varias disciplinas por un solo sujeto, ni mucho menos, como queda señalado, de la ciencia a la que pertenecen.

En la historia de los grandes genios (como Leonardo D’Vinci) o grandes arquitectos especialistas (como L. Benévolo) se ha llegado a dar el caso del conocimiento y dominio de varias ciencias por un solo individuo, pero de ningún modo es la generalidad de quien se dedica a pensar o a edificar ('poner') 'mundo'. La generalidad señala hacia el distanciamiento epistemológico entre el conocimiento o dominio de una o varias ciencias y su fragmentación puesta de manifiesto en la hiperespecialización disciplinaria de ellas.

\section{4) Oposición al 'positivismo' de las ciencias sociales. Una lucha necesaria}

Desde la aparición del Curso de filosofía positiva de Comte, hacia los años 30's del siglo XIX cuando por primera vez es empleado por él el término "sociología", la historia, la geografía, y la arqueología, por citar sólo algunas de las ciencias que componen hoy la constelación de las ciencias sociales, ya tenían siglos de presencia en el mapa de las ciencias. A mediados de los años 40 de ese siglo con la elaboración de la Ideología alemana (obra de Marx y Engels que no fue conocida sino hasta el siglo XX), se dio un nuevo impulso al desarrollo de las ciencias sociales, bajo su propuesta de concepción materialista de la historia mejor conocida como "materialismo histórico", alimentada poco más de una década después por la aparición del libro El origen de las especies (1859), de Charles Darwin. Desde entonces la polémica entre las ciencias naturales y las ciencias del hombre respecto a sus analogías y diferencias, pero, sobre todo, por las diferencias metodológicas y de procedimientos, han sido motivo de fuertes discusiones una y otra vez, desde el darwinismo social de Spencer, la llamada filosofía de la vida y la cultura de Georg Simmel, hasta las polémicas de Karl Popper y Adorno, Habermas y Albert, en los años 60's del siglo XX.

A comienzos de estos años sesenta se llevó a cabo en Tubinga, Alemania, la famosa "disputa sobre el positivismo en la sociología alemana", en donde se confrontaron dos de las más influyentes escuelas del pensamiento social en el siglo XX: el Racionalismo Critico (K. Popper, H. Albert) y la Escuela de

\footnotetext{
45 Esta problemática se pone en evidencia cuando se quiere "traducir" a otros idiomas como el alemán o el ruso, por mencionar algunos, en los que no existe la figura de tal "tipo de profesional" y el currículo equivalente tendría que ser buscado bajo otras "ofertas académicas". La Universidad de San Diego, California (EUA), ofrece, por ejemplo, la "profesión" de Física aplicada a la ingeniería.
} 
Francfort (T.W. Adorno, J. Habermas) bajo el tema central del encuentro llamado "Lógica de las ciencias sociales". Popper y Albert defendían una unidad metodológica para las ciencias naturales y sociales, mientras que Adorno y Habermas establecían una distinción epistemológica y política entre las dos. Para el Racionalismo Crítico, las ciencias sociales deben liberarse de la tendencia a explicar los fenómenos sociales sobre la base de utopías inmunes a la falsabilidad empírica. Para la Escuela de Francfort, en cambio, las ciencias sociales deben ser algo más que análisis empírico y convertirse en una verdadera "teoría crítica de la sociedad", capaz de explicar dialécticamente los fenómenos ideológicos que imposibilitan la realización de una sociedad emancipada.

Es muy notorio el hecho de que en esta polémica hace presencia una lucha ideológica y, a partir de ella, se ha tratado de imponer desde hace más de un siglo, el condicionamiento de las ciencias sociales a la misma estructura y metodología que las ciencias de la naturaleza, sin pugnar por el respeto a los enfoques diversos de las ciencias sociales. Esta última opción enlaza con la postura tradicional, que sostiene que lo propio de las ciencias sociales, es la comprensión de la sociedad y la cultura, es decir, del hombre en el plano de la complejidad fenoménica propia de su multidimensionalidad. Le es propio a estas ciencias contemplar su objeto de estudio, el hombre, como un ser social libre, autónomo y no sometido al destino, aunque sí dentro del marco de los condicionamientos psicológicos, ambientales, políticos e históricos, y que se manifiesta activamente a través de la dimensión lingüística, de sus producciones e instituciones culturales y sociales, y no como un ser biológico sometido a leyes deterministas.

Sin duda en este proceso cognitivo existe una coincidencia en la naturaleza de lo que se estudia y de quien lo estudia, produce la peculiaridad de que las ciencias de la sociedad y del espíritu pueden comprender desde dentro, y no solamente entender desde fuera el objeto que se investiga, y, por el otro, el carácter problematizador de la "objetividad científica", difícil de lograr si se pretenden conceptos objetivos y leyes universales. En el estudio de los fenómenos sociales intervienen los prejuicios, las ideologías y los juicios de valor. Son las dos caras, positiva y negativa, del llamado método de la comprensión-interpretación, un método con alta dosis de subjetividad. Si a esto se le suma la dificultad de producir fenómenos tras la experimentación en materia social, o reproducirlos en circunstancias idénticas, la dificultad de analizar las predicciones, y el problema de generar enunciados universales en las ciencias sociales, en el caso de que en estas ciencias pudieran formularse generalizaciones con el rigor necesario. De este modo, cuando en las ciencias naturales se supone la regularidad de los fenómenos bajo la idea de que los efectos semejantes son producidos por causas semejantes, de modo que, en la igualdad de circunstancias y objetos, los fenómenos son los mismos. En las ciencias sociales, los objetos de estudio, esto es, los hombres, en circunstancias semejantes generan actos y acontecimientos diferentes.

De acuerdo con Ernst Nagel es posible identificar la diferencia de metodología entre las ciencias naturales y las ciencias sociales por la unanimidad entre los investigadores respecto a las ciencias naturales por tres identidades básicas: 1) los hechos que hay que explicar, 2) las explicaciones satisfactorias de los hechos si es que las hay, y 3) los procedimientos de investigación que permiten hallar las explicaciones de los hechos. Ante esto las ciencias sociales, en comparación con las ciencias naturales, no gozan de suficiente unanimidad, ni sobre cuestiones de contenido, ni sobre cuestiones de método, y hasta es posible dudar acerca de si estas ciencias "aportan leyes estrictamente universales acerca de fenómenos sociales" 46 , lo cual no es sinónimo de una falta de cientificidad sino de una exaltación de la diferencia entre la naturaleza misma de las ciencias y de la complejidad que envuelve a los fenómenos que tienen como objeto de estudio.

En la segunda mitad del siglo XX, ciencias como la psicología social, la antropología social, la semiología, la geografía humana, la etnografía, la pedagogía, entre otras, han logrado desarrollar sus campos investigativos gracias a la abundancia de material empírico que mana por doquier, consolidando la aprehensión de sus objetos de estudio, métodos e instrumentos de trabajo; otras disciplinas tales como la de estudios del territorio, estudios urbanos y metropolitanos, por tener objetos de estudio transdisciplinarios, pugnan por la consolidación de sus respectivos campos disciplinarios sin que esto

${ }^{46}$ E. Nagel, La estructura de la ciencia, Buenos Aires, Paidós, 1981, pp. 405-406. 
signifique unanimidad de enfoques ni unilateralismo científico, sino por el contrario, abre distintas posibilidades de asunción de la multidisciplinariedad científica que es o debería ser parte del trabajo colectivo, aspecto lejano a estas alturas del crecimiento del campo científico y de la complejidad social. A cualquier investigador social serio de nuestro tiempo le queda clara la imposibilidad de que un solo investigador social lo pueda estudiar todo, si al análisis empírico hacemos referencia, la época del enciclopedismo ha quedado atrás, allende el siglo XX, no así la necesidad del análisis holístico ni mucho menos crítico, que seguirá siendo una necesidad y una aspiración para el conocimiento profundo de la realidad humana.

\section{5) Razón "fracturada", "teoría de la complejidad" y capitulación de la investigación científica}

La fracturación de la realidad para su mejor conocimiento mediante la hiperespecialización, es una expresión de lo que denominamos "fractura de la razón", es acompañada por causales epistemológica que caracterizan la ciencia de la modernidad y de nuestro tiempo, el tiempo del neoliberalismo económico, la globalización, la posmodernidad y la sostenibilidad: la "matemátización" del conocimiento científico de la naturaleza, el positivismo; la confusión académica entre ciencia y disciplina; y la dupla "teoría de la complejidad" - transdisciplinariedad.

¿Unidisciplinariedad? Sí, en efecto. La existencia de "profesionistas" que se forman en el dominio de un determinado "objeto de estudio", son testigos anónimos de una selectiva "fragmentación de ese objeto", esa es la labor de las universidades e institutos que brindan oportunidades formativas (generalmente de niveles de "posgrado") gracias a la correspondiente "selectiva fragmentación de las ciencias".

¿Interdisciplinariedad? Ella también es evidente cuando analizamos las interconexiones de las disciplinas, como en los ejemplos vistos anteriormente. También lo podemos observar por doquier, cuando analizamos los resultados en la "calidad" y la "eficiencia" del trabajo entre "especialistas" que ponen a funcionar las instituciones e instancias de la vida colectiva como hospitales, universidades, partidos políticos, sedes de gobierno, ministerios estatales, etc.

¿Multidisciplinariedad? Es también muy factible cuando la "apertura del campo" (Heidegger) que se estudia aumenta su grado de complejidad e incluye varios segmentos del "objeto de estudio" y varios modos de comportamiento o manifestación de los fenómenos estudiados. Exige, por tanto, la visión múltiple de un "especialista" en varias disciplinas o del trabajo colectivo entre especialistas que asumen la labor explicativa y reguladora -en ocasiones- de la porción de realidad con la que lidian. En las disciplinas atrás comentadas, se llegan a dar casos de médicos que, además de ser "especialistas en pediatría", son también "ortopedistas", "osteólogos" y "terapeutas" auxiliares en todo tipo de lesiones óseas; de la misma forma que, en el caso de la ingeniería civil, existen "proyectistas" que diseñan estructuras no complejas como las de edificios pequeños o "casas habitación y son también "constructores". Dada la imposibilidad de que con una sola rama del conocimiento de la realidad sea suficiente para explicar tales objetos de mayor complejidad, éstos fuerzan con flagrancia al desbordamiento de las potencialidades cognitivas que brinda una sola disciplina y surgen entonces "multidisciplinas" como la "medicina forense" o la "antropología física", la "paleoantropología" o la "antropología comparada", la "etnohistoria o la "etnomusicología", por tan solo citar algunas. En estos casos la multidisciplina es también multi-ciencia, por interconectar varias ciencias.

¿Transdisciplinariedad? Sí, pero como una cualidad proveniente del desbordamiento del objeto estudiado y no de sumatoria de esfuerzos de investigadores preocupados por conocer objetos de estudio que sobreabundan sus conocimientos fragmentarios. Se trata de un modo de comprensión de la realidad social contemporánea que parte de la idea del reconocimiento de un mundo constituido como un todo indivisible y difícil de aprehender individualmente, cuya composición que se ha vuelto cada vez más 
"compleja". La "transdisciplinariedad" es hasta hoy una aspiración epistemológica integracionista "pluralista" con repercusiones éticas. Estas últimas, sin duda, dignas de ser consideradas por la relevancia pragmática que se le asigna a la multivocidad incluyente en un tiempo de reacomodo social de lo que hemos resaltado como característico de la "condición posmoderna". Se agrega, entonces, un elemento más a los componentes epistemológicos de la llamada transdisciplinariedad: la "teoría de la complejidad" o "pensamiento complejo".

El llamado "pensamiento complejo" y la "transdisciplinariedad" son altamente acordes con lo que hemos destacado aquí como una sintomatología de la "condición posmoderna". Surgió silenciosamente cuando eran hegemónicas dos ideologías hegemónicas que sustentaron y sirvieron de fundamento epistemológico a los proyectos de humanidad que ambos habían apoyado: el positivismo como soporte de la sociedad dividida en clases (hegemónicas y subalternas), el capitalismo; y la "dialéctica", empleada -pese a su potencialidad de crítica radical- en forma maniquea por la burocracia entronada en las esferas del poder en el "socialismo apócrifo", que administró y acalló persecutoriamente todo pensamiento promotor de la revolución dentro de la revolución científica y social.

Esa forma de pensamiento que resguardaba la idea de que el mundo era difícil de conocer por tratarse de un conjunto intrincado y que requería de su abordaje de manera "multidisciplinar" y "multirreferenciada" se denominó "pensamiento complejo". Debía incluir recursos nuevos y fundantes como la cibernética, la teoría de sistemas y la teoría de la información incipientes por esos años, pero altamente llamativas y "neutrales". Actualmente la "transdisciplinariedad" es una forma de comprensión concebida como investigación integradora ${ }^{47}$ poco coincidente con otra de sus acepciones, la de que se trata de un "principio de unidad del conocimiento más allá de las disciplinas" 48 . En este enfoque del saber se considera el empleo de un conjunto de métodos para relacionar el conocimiento científico, la experiencia extra-científica y la práctica de la resolución de problemas orientados hacia los aspectos del mundo real y no sólo a los del debate científico; aborda "conjuntos problemáticos" con capacidad para funcionar sistémicamente en lugar de territorios del saber epistemológicamente delimitados, volviéndose necesario un "enfoque integrador de saberes".

Edgar Morin, uno de los fundadores y representantes de la "teoría de la complejidad", propuso la idea según la cual para realizar la comprensión de un mundo complejo, era necesario otro tipo de conocimiento alternativo al conocimiento en boga (la uni / inter / multi / disciplinariedad) y, desde luego -debe decirse con especial énfasis- a la metafísica, el positivismo y la dialéctica de la "totalidad concreta", por esos años (los años 60's) también vigente. ${ }^{49}$

La "teoría de la complejidad" o "pensamiento complejo" surgió como un modo alternativo a los métodos (la teoría negativa, el positivismo y la dialéctica) o modos de comprensión de la realidad en pugna. Emergió con una evidente carga ideológica pero sin dar un salto sobre las ya existentes formas de vinculación disciplinaria hasta colocarse como alternativa epistemológica de buena parte de investigadores sociales, políticos y planificadores que ya no defienden la dialéctica como forma de aprehensión crítica de la realidad, aspecto al que denominamos aquí capitulación de la investigación científica a la razón fragmentada, ahora bajo la figura del "pensamiento complejo" o "teoría de la complejidad".

La realidad compleja existe sin duda, pero no es sinónimo de "teoría de la complejidad", "pensamiento complejo", ni mucho menos, de sus fundamentos metodológicos y epistemológicos en la teoría de sistemas y el pensamiento matemático que subyace en ella. Sin duda alguna, nuestro mundo de comienzos del siglo XXI es mucho más complejo que el mundo complejo que ya entonces el Hegel de comienzos del siglo XIX anunciaba en su Fenomenología del espiritu de 1806, que el del Marx que escribió "El método de la economía política" en 1857; el del Braudel que decidió detener su estudio de la historia del capitalismo en su Civilización material, economía y capitalismo (1969) en el siglo XVIII, por la complejidad

47 Cfr., Aronson Mittelstrass, La emergencia de la ciencia transdisciplinar, Santiago, Universidad de Chile, 2003, p. 18.

48 Basarab Nicolescu, "Manifesto of Transdisciplinarity", New York, State University of New York Press, 2002.

${ }^{49}$ Cfr., Karel Kosík, Dialéctica de lo concreto, México, Grijalbo, 1976. 
económica que implicaba. A ello se han expresado ideas como las de Eric Hobsbawn respecto a si vivimos en un mundo "globalizado" o en proceso de "globalización" son aplicables también a la idea de vivir en un mundo "complejo". Él prefería decir que vivimos en un mundo todavía-no "globalizado" sino en proceso de "globalización" y que seguramente dentro de cuarenta años lo estaremos más que hoy; ${ }^{50}$ y lo será mucho más dentro unas cuantas décadas en que los patrones fosilistas de consumo energético se hayan agotado y la humanidad habite cada vez en más megaciudades.

Al desprestigio ideológico político del "socialismo apócrifo" le siguió el "desprestigio epistemológico" de la dialéctica. Este hecho le sentó bien a los administradores de la "ciencia normal" 51 positivistafragmentaria: ahí donde impera un principio básico anquilosado, prevalecen las sociedades burocratizadas. Toda estandarización y toda "normalidad" aseguran una actitud acomodaticia. Las revoluciones (sociales o científicas) son siempre incómodas para el statu quo y los pensadores que las gestan serán también siempre huéspedes incómodos, aunque habiten su propia tierra.

Como hemos visto ya, para la construcción explicativa de la realidad, ella ha sido dividida en "campos de objetos"; estos, a su vez, en "objetos de estudio" que, por último, en su individualidad, es fragmentado en lo que podríamos denominar "porciones objetuales". De manera correspondiente, la "realidad" se ha dividido - para su estudio- en "clases de ciencias" que, a su vez, se descompone en "ciencias individuales" y éstas se han fragmentado en "disciplinas". En el supuesto de que a cada "objeto de estudio" tomado de la realidad le corresponde una ciencia, la división de esa ciencia en "disciplinas" es la expresión de la "fragmentación de ese objeto". La "ecuación" propuesta por Marcuse [Razón = Verdad = Realidad] queda sustituida en el ámbito epistemológico de la "ciencia normal" (ciencia "real") como la ecuación reducida a su mínima expresión [disciplina = explicación (teoría y método) = "porción objetual"].

Desde el punto de vista de una posible consideración general de la relación entre razón y realidad, en rigor, la "transdisciplinariedad" no es ni una teoría ni un método, puesto que el prefijo trans alude a la acción de "atravesar" o "ir a través de", en este caso, de las "disciplinas". Quiere sugerir una acción, una intención (deseo o aspiración) o una posibilidad: la de "ir a través de las disciplinas", "atravesar disciplinas" o simplemente "traspasar disciplinas".

¿Mediante cuál sistema explicativo y bajo qué métodos? Ese es precisamente el papel de la llamada "teoría de la complejidad", una teoría "plural" que por nacer de las aspiraciones de una triada acomodaticia del statu quo (la cibernética, la teoría de sistemas y la teoría de la información) despierta grandes sospechas por no plantear ni mucho menos garantizar el destierro de la "matematización de la realidad": el "proyecto matemático de la naturaleza", que subyace a la "razón instrumental"; más aún cuando los métodos a los que se acoge coinciden en sus fundamentos con la visión positivista y pragmatista del mundo.

Se trata de un discurso paracientífico que parece hasta hoy poco probable de concretarse como integración epistemológica holística si no se revolucionan, inicialmente, las condiciones del trabajo científico de la "ciencia normal", ni se trastoca el statu quo de los fundamentos que motivan las "fracturas de la razón" desde la perspectiva que hemos esbozado a lo largo de estas reflexiones, bajo la necesidad de una articulación del substrato negativo del pensamiento y el mundo objetivo (substrato positivo), desprendiéndose del desdén de su relación dialéctica.

\footnotetext{
${ }^{50}$ Eric Hobsbawn, "Pequeño mundo global”, en Rev. Memoria No. 134, México, abril, 2000, p. 6.

51 Aquellos que como en la Universidad de Nuevo León de los años 90’s en México pretendieron "cerrar” las carreras de Historia, Filosofía y Letras Hispánicas para que -dijeron- la Universidad (UANL) "adecuarse a las necesidades del mercado" y porque "no gradúa desempleados" (La Jornada, 9/Feb./05).
} 


\section{Conclusión: sobre 'crisis sistémica' y 'crisis epistemológica'}

Nos encontramos en mejores condiciones para señalar hacia un conjunto de respuestas posible en relación con la interrogante formulada al inicio de esta revisión crítica.

\section{Cuaterna predominante}

- El conjunto del mundo de la vida en la cultura contemporánea está permeado por cuatro procesos históricos por los que transitamos: el neoliberalismo, la globalización, la llamada "posmodernidad" y el "desarrollo sostenible". Desde estos procesos históricos es posible construir las tendencias epistemológicas de la labor investigativa del campo científico contemporáneo.

- La revisión de aspectos que resultan fundamentales en las definiciones-clave de los problemas de la labor científica se levantan sobre condiciones siempre-por-construir y nos invitan a mantener una actitud expectante de "ojos abiertos" y "oídos atentos", ahí donde los fenómenos que nos envuelven son descomunales y abominables (neoliberalismo, globalización, posmodernidad, sostenibilidad), entonces se vuelve justa la conducción del pensar hacia el espacio que le proporciona un refugio apropiado para la revisión crítica.

Relación ciencia - sociedad

- La relación entre sociedad y ciencia señala un vínculo innegable que, mediante su reconocimiento, se da lugar a la identificación de elementos históricos que permiten comprender y explicar cómo se condiciona o hasta qué límite se determina un elemento respecto al otro.

- El carácter problemático de la investigación científica debe ser pasado por la criba de los viejos temas que se mimetizan con las coyunturas y períodos históricos inducidos por los cambios sociales sistémicos: la "técnica maquinista", la "razón instrumental", y, en el ámbito epistemológico, el "empirismo" y el "positivismo", revestidos ahora de la propuesta del "pensamiento complejo" radicalmente alejado de la "razón fracturada".

- Llamamos aquí "crisis de la ciencia" al ocultamiento de la verdadera crisis que se nos vino encima con el neoliberalismo, que subsume todos los ámbitos de la vida social. Una crisis de proyecto social y civilizatorio acaecida tras el desplome del "socialismo real".

Periodización histórica de la ciencia

- La relación histórica entre ciencia y sociedad permite explicar la duración corta o prolongada por la que se transita, si se trata de una coyuntura, un período o una época histórica que extiende su dominio y señala los rasgos predominantes de este dominio.

- Sin duda alguna, nos encontramos en el período histórico del desarrollo de la ciencia que Bachelard denominó "del nuevo espíritu científico", tercer periodo, posterior a 1905 (aparición de la teoría de la relatividad), que anunció revoluciones científicas fundamentales, pero que, sin duda alguna, tiene como referente fundamental a la razón.

Razón instrumental y ciencia normal

- Debemos conservar a la razón y a la verdad como ejes generales de referencia a partir de los cuales se construye toda argumentación ideológica y política, muy a pesar de las posibles manipulaciones hegemónicas y sistémicas de las que pueden ser "bandera".

- Es necesario hacer patente con seriedad y profundidad la idea de un "proyecto matemático de la naturaleza" visualizado por Heidegger, puesto que desde ese fundamento explicativo se devela la relación parasitaria del hombre hacia la naturaleza. Este aspecto hace resaltar la crítica marxista formulada desde Marx hasta la teoría crítica de los pensadores de la Escuela de Francfort (Horkheimer, Adorno, Benjamin, Marcuse, Habermas, Schmidt) tras una actitud calculadora mediante el uso y abuso irracional de la técnica.

\section{Crítica al positivismo}


- Es evidente que el positivismo, por ejemplo, el de la ciencia de la biología médica o en cualquier estudio fragmentario de la naturaleza, desvirtúa la comprensión de la realidad como totalidad cuando, bajo el supuesto cientifismo, fractura el todo mediante el uso de tan solo una porción de datos.

- Es necesario destacar que en la "disputa del positivismo en las ciencias sociales" durante los años 60's, el núcleo de la defensa del positivismo es la cerrazón a la experiencia de la totalidad dominante, su ideologización (en tanto que falsa conciencia) mediante una supuesta "neutralidad ideológica" (pluralista), así como una "fragmentación del objeto". Esto implicó, de manera soterrada, el olvido del "cuerpo muerto" tanto del idealismo como del formalismo del siglo XIX. En esa discusión el materialismo mostró la mediación entre la teoría y la práxis y mostró también que una modernidad distinta a la capitalista es posible.

- Recordamos y enfatizamos que en la polémica contra el positivismo se pone en juego el sentido real del papel de la ciencia y de los científicos, filósofos y pensadores que la hacen posible, se oculta la relación fines y medios. Y que la ciencia ni sus métodos son, en verdad, medios y no fines en sí mismos. 52 Que de ninguna manera, la ciencia podría quedar fuera de las intenciones de la vida social en su conjunto.

Capitulación de la investigación cientifica

- Es necesario reconocer que, en el mejor de los casos, la subordinación al empirismo, el positivismo y la difusa idea de un "pensamiento complejo", es en realidad un eclecticismo derivado del desencanto y abandono de la teoría que anunció una nueva sociedad y un nuevo tipo de "razón crítica" basada en la dialéctica de la historia y, con ella, de la puesta en movimiento de los opuestos, devenidos en transformación del "mundo de la vida".

- La capitulación al empirismo y al positivismo (traducido en manejo de datos fragmentarios y métodos parcelarios) es un ocultamiento acomodaticio de las intencionalidades anquilosadas y oficializantes en los que la vida académica coloca a los investigadores. Se convierte en una "zona de confort", una suerte de "silla mecedora" de la "quietud social" y el pensamiento acrítico enajenado.

- Después de poco más de doscientos años en que la realidad, en efecto se ha vuelto más compleja, tendría razón Hegel aún hoy al decir que la "tediosa apariencia de la diversidad" 53 es mera apariencia, cuando lo que hay detrás es el ocultamiento que trae tras de sí la enajenación humana, lo cual es, en verdad, como ya lo demostró Marx, el ocultamiento de las posibilidades reales para que el desarrollo tecnológico pueda brindar mayores condiciones para la satisfacción completa de las necesidades de la población mundial. La aceptación de una "tediosa apariencia de la diversidad", no es desde luego la negación de la existencia de una cierta "complejidad" sino la denuncia de lo que ella oculta: todo un proceso de enajenación que trasciende al conocimiento mismo.

- De lo anterior surge una diferencia fundamental: realidad compleja es totalmente distinto de "teoría de la complejidad", la primera, es una resultante histórico material, una "civilización material" y social, una realidad (a mayor progreso social, mayor complejidad), la segunda un método de análisis que toma la teoría de sistemas (matemáticos) como fundamento de su epistemología.

- Recordamos y pretendemos hacer patente para el "imaginario científico" contemporáneo (la "memoria epistemológica") que, la "dialéctica de la "totalidad", y no la teoría sistémica del "pensamiento complejo", no es un "punto de vista", ni una categoría afirmativa sino la conciencia consecuente de la diferencia en la diversidad. 54

- La dialéctica como método crítico sólo podrá legitimarse -como sugería Adorno- volviendo a traducir el contenido del que surgió: el de la vida toda entendida ella como unidad y "totalidad", como experiencia de la mediación de todo lo individual a través de la totalidad social objetiva, en lugar de

\footnotetext{
52 Adorno, Theodor, Epistemología y ciencias sociales, Valencia, Frónesis-Cátedra, 2001, p. 94.

53 Cfr., Hegel, Fenomenología..., p.14.

54 Adorno, Theodor, Dialéctica negativa, Madrid, Taurus, 1990, p. 13.
} 
la "fragmentación" y la correspondiente "hiperespecialización" individualizada de los -en el mejor de los casos- "research", salidos de la Academia fragmentaria y perseguida por el productivismo atroz de los órganos de control de calidad de la "productividad científica", la ciencia "nacional" y la llamada "excelencia académica".

- Es necesario recuperar el sentido y la intención que tanto Adorno como toda la Escuela de Francfort en la práctica sostuvieron: la idea que va más allá del dogmatismo de la tercera internacional según la cual "la filosofía sigue vigente porque se dejó pasar el tiempo de su realización". ${ }^{55}$

Atisbar en estos señalamientos podría propiciar que el desempeño de nuestro trabajo académico, investigativo, y -si fuera el caso- la acción política, podría influir en la visualización causal de estas y otras circunstancias, para formular las preguntas fundamentales, así como dirigir y alumbrar mejor nuestras respuestas.

\section{Bibliografía}

Adorno, Theodor, Dialéctica negativa, Madrid, Taurus, 1990.

Adorno, Theodor, Epistemología y ciencias sociales, Valencia, Frónesis-Cátedra, 2001.

Bachelard, Gaston, La formación del espiritu científico, México, Siglo XXI, 2003.

Benjamin, Walter, La obra de arte en la época de su reproductibilidad técnica (Urtext), México, Itaca, 2003. Tesis sobre la historia y otros escritos, México, Contrahistorias, 2005.

Echeverría, Bolívar, Vuelta de siglo, México, Era, 2006.

"Introducción. Benjamin, la condición judía y la política", en Tesis sobre la historia y otros fragmentos, México, Contrahistorias, 2005. Definición de la cultura, México, UNAM-Itaca, 2010. Modelos elementales de la oposición campo-ciudad, México, Itaca (Jorge Gasca, Editor), 2013.

Gasca, Jorge, Pensar la ciudad. Entre ontologia y hombre, México, IPN, 2007. La ciudad: pensamiento crítico y teoría, México, IPN, 2005.

Habermas, Jürgen, Ciencia y técnica como "ideología", México, Red Editorial Iberoamericana, 1996.

Harvey, David, La condición de la posmodernidad, Buenos Aires, Amorrortu, 1998.

Hegel, GWF, La Fenomenología del espiritu, México, Fondo de Cultura Económica, 1985.

Heidegger, Martin, Holzwege, Frankfurt am Main, Vittorio Klostermann, 1980. Sendas perdidas, Buenos Aires, Losada, 1979.

Hitos, Madrid, Alianza, 2000.

Conferencias y articulos, Barcelona, Serbal, 1994.

-"La pregunta por la técnica".

-“QQué quiere decir pensar?".

¿Qué es metafisica? y otros ensayos, Buenos Aires, Fausto, 1996.

"La pregunta por la técnica", en Filosofía ciencia y técnica, Santiago de Chile, Universitaria, 1997.

Herder, Diccionario de filosofía, Madrid, 2002.

Hobsbawn, Eric, "Pequeño mundo global", en Rev. Memoria No. 134, abril, pp. 5-11, 2000, México DF

Horkheimer, Max, Crítica de la razón instrumental, Madrid, Trotta, 2002.

Horkheimer, Max; Adorno, Theodor W., Dialéctica de la ilustración, Madrid, Trotta, 1998.

Kant, Immanuel, Crítica de la razón pura, Buenos Aires, Losada, 2003.

Kosík, Karel, Dialéctica de lo concreto, México, Grijalbo, 1976.

"La ciudad y lo poético", Rev. Nexos, Febrero, 1998.

Kuhn, Thomas. S., La estructura de las revoluciones cientificas, México, FCE, 1986.

La Jornada. URL: http://firgoa.usc.es/drupal/node/13738/print (9/Feb./05), México, 2005.

Lukács, Georgy, Historia y conciencia de clase, México, Grijalbo, 1969.

Lyotard, Jean F., La condición posmoderna, Madrid, Cátedra, 1998.

Marcuse, Herbert, El hombre unidimensional, México, Planeta-Artemisa, 1985.

55 Adorno, Theodor, op. cit., p. 11. 
Marx-Engels, La ideología alemana, Montevideo, Ediciones Pueblos Unidos, 1974. Cuadernos de París, México, Era (tr. Bolívar Echeverría), 1980.

Mittelstrass, Aronson, La emergencia de la ciencia transdisciplinar, Santiago, Universidad de Chile, 2003.

Nagel, E., La estructura de la ciencia, Buenos Aires, Paidós, 1981.

Nicolescu, Basarab, Manifesto of Transdisciplinarity, State University of New York Press, New York, 2002.

Pereyra, Paolo Cesar. (2007). "La ciudad: sobre la importancia de nuevos medios para hablar y pensar las ciudades", en Rev. Mundo Siglo XXI, Núm. 9, verano de 2007, México, Centro de Investigaciones Económicas, Administrativas y Sociales - IPN, pp. 69-80.

Platón, "La República”, en Diálogos, México, Porrúa, 1998.

Vattimo, Gianni, En torno a la posmodernidad, Colombia, Anthropos, 1994.

Weber, Max, La ética protestante y el espiritu del capitalismo, México, Colofón, 1999.

Werner Sombard, Der moderne Kapitalismus, Leipzig, Verlag von Duncker \& Humbolt, 1902. 